\title{
Immune complexes in synovial fluid and serum from patients with disseminated gonococcal infection: evidence for local immune complex formation within the joint
}

\author{
WILLIAM C SHIEL JR, ${ }^{1}$ BRIAN S ANDREWS, ${ }^{1}$ GEORGE J FRIOU, \\ FRANC A BARADA JR, ${ }^{2}$ EVE SCOPELITIS, ${ }^{3}$ AND DAVID A MARTIN ${ }^{1}$
}

From the ${ }^{1}$ Division of Rheumatology and Clinical Immunology, Department of Medicine, University of $\frac{0}{2}$ California, Irvine, CA; the ${ }^{2}$ Division of Rheumatology, Department of Medicine, University of Virginia, is Charlottesville, VA; and the ${ }^{3}$ Division of Rheumatology, Department of Medicine, Louisiana State University, New Orleans, LA

SUMmarY Twenty one patients with acute arthritis associated with disseminated gonococcal $\stackrel{\rho}{?}$ infection (DGI) were studied. Synovial fluid (SF) from 14 and serum from 15 (matched in eight) $\bigcirc$ were assayed for the presence of immune complexes (IC) by the Raji cell immunofluorescent $\stackrel{0}{\circ}$ assay (Raji IFA) and the ${ }^{125} \mathrm{I}$-Clq polyethylene glycol (PEG) binding assay. Higher levels and $\stackrel{\mathbb{\Phi}}{\sim}$ frequency of IC were detected in the SF by both IC assays and these were associated with $a \overrightarrow{0}$ significant increase in complexes containing IgM over serum $(\mathrm{p}<0 \cdot 02)$. Complexes containing ${ }_{\circ}^{\circ}$ IgG were found predominantly in serum and were infrequent in $\mathrm{SF}(\mathrm{p}<0.003)$. These dat. suggest that the arthritis of DGI may result from primary immune complex formation within the synovial cavity after local antibody synthesis within the synovium in response to gonococcal seeding.

Key words: gonococcal arthritis, Raji cell assay.

Neisseria gonorrhoeae is the most common cause of infectious arthritis in adults. ${ }^{12}$ The pathogenesis of the arthritis associated with disseminated gonococcal infection (DGI) is unclear in many situations, though the organism can be cultured from SF in $30-47 \%$ of cases. ${ }^{3-6}$ A negative SF culture in DGI may be due to the absence in SF of viable organisms, which have fastidious growth requirements in culture, ${ }^{7}$ or because gonococci enter the synovium but not the SF.

Immune complexes are associated with disease in animals ${ }^{8}$ and humans. ${ }^{9-14}$ It has been accepted that circulating IC deposit in various tissues, such as the renal glomerulus and synovium. ${ }^{15}$ Recent studies have suggested that antigen may localise initially in tissues, followed by local binding of circulating

Accepted for publication 9 April 1986.

Correspondence to Dr Brian S Andrews, Division of Rheumatology and Clinical Immunology, Medical Sciences I, Department of Medicine, University of California, Irvine, CA 92717, USA. antibody with the formation of in situ IC. ${ }^{16}$ As the SF from patients with active synovitis and? documented extrasynovial gonococcal infection is often sterile it has been suggested that the arthritis may be a manifestation of a systemic IC disease. ${ }^{6}{ }^{17-20}$ O Complexes have been reported in serum and SF in DGI using the Raji cell radioimmunoassay, the $\mathrm{Clq}$ 을 binding assay, and the platelet aggregation assay. ${ }^{71820}$ When a monoclonal rheumatoid factor assay is employed or cryoglobulins are measured, $N$ however, the presence of IC has not been shown. ${ }^{19} 20$ No correlation has been observed between the IC found in serum and SF. ${ }^{20}$

The asymmetrical distribution of arthritis found in? DGI is not typical of the arthritis in diseaseso believed to reflect the deposition of circulating ICD within synovium, such as hepatitis B virus infection,?+? serum sickness, and systemic lupus erythematosus. $\frac{T}{0}$ In classical IC diseases the arthritis is symmetrical. ${ }^{-1}-130$ Further, the detection of gonococcal organisms in 
SF and synovium by Gram stain, ${ }^{\circ}$ the presence of the organism on culture in $30-47 \%$ of cases,,-6 the demonstration of the gonococcus in synovial tissue by electron microscopy, ${ }^{21}$ and the detection of the antigen in SF by counterimmunoelectrophoresis, ${ }^{22}$ all suggest that the organism itself localises primarily within synovium and may spread to SF. Gonococcal antigen(s), which would then be liberated, could initiate a primary antibody response by B lymphocytes within the synovium. Local formation of IC could then result within the synovium and SF.

In order to determine whether IC might be produced locally we first quantified IC in serum and SF to see if higher levels were present in SF and, by using the Raji IFA, attempted to identify the immunoglobulin class(es) present in IC in serum and SF. If complexes containing predominantly IgM were present in SF at the onset of the arthritis, while complexes containing IgG were simultaneously detected in serum, this might suggest a local primary antibody response.

\section{Patients and methods}

Patients with DGI in this study, who were otherwise clinically healthy, were from the University of California Irvine Medical Center, Louisiana State University Medical Center, and the University of Virginia Medical Center. Informed consent was obtained for this study. Disseminated gonococcal infection was defined by the presence of typical arthritis, skin lesions (petechial or vesiculopustular), a rapid clinical response to antibiotics, and ideally, culture positivity for $N$ gonorrhoeae. Eighteen of 21 patients studied had at least one site of bacteriologically recorded infection with $N$ gonorrhoeae from either urethra, cervix, SF, blood, pharynx, or rectum. Three patients were culture negative but showed classical cutaneous and joint findings with a dramatic response to appropriate antibiotic therapy. All initial specimens were obtained before antibiotic therapy. The presence of accompanying joint pathology or any disease associated with circulating IC excluded patients from this study. For controls, serum was obtained from six patients with gonococcal urethritis alone, SF from six seropositive patients with rheumatoid arthritis (RA), and SF from five patients with gout or degenerative joint disease.

Immune complexes were determined in both SF and serum by the Raji IFA ${ }^{23}$ and by the ${ }^{125} \mathrm{I}-\mathrm{Clq}$ polyethylene glycol binding assay. ${ }^{2+}{ }^{25}$ Before testing, $200 \mu \mathrm{l}$ of SF was incubated with $10 \mu \mathrm{l}$ bovine hyaluronidase $(1500 \mathrm{IU} / \mathrm{ml}$ in distilled water $)$ at $37^{\circ} \mathrm{C}$ for 30 minutes. The Raji cell IFA was performed by incubating $2 \times 10^{6}$ Raji cells in $25 \mu \mathrm{l}$ of $1: 4$ test serum or hyaluronidase treated SF in phosphate buffered saline $\mathrm{pH} 7.4$ (PBS) for 45 minutes. Cells were washed three times in RPMI 1640 medium at $4^{\circ} \mathrm{C}$ and then incubated for 30 minutes at $4^{\circ} \mathrm{C}$ with $25 \mu \mathrm{l}$ of the appropriately PBS diluted, fluorescein isothiocyanate conjugated Fab' rabbit antihuman IgG, IgA, and IgM (heavy chain specific). Cells were then washed three times in PBS containing $1 \%$ bovine serum albumin at $4^{\circ} \mathrm{C}$ and a cytocentrifuge preparation obtained. Cells were examined by fluorescence microscopy and the amount of cell surface positivity graded from $0-4+.{ }^{23}$ Appropriate controls consisted of Raji cells incubated in normal human serum (NHS) alone, PBS, NHS containing heat aggregated human IgG at a concentration of $400 \mu \mathrm{g} / \mathrm{ml}$ for $4+$ positivity, and aggregates incubated in serum which had been decomplemented by heating to $56^{\circ} \mathrm{C}$ for 30 minutes. The ${ }^{125} \mathrm{I}-\mathrm{C} 1 \mathrm{q}$ PEG liquid phase binding assay was performed using a modification $^{24}$ of the method described by Zubler $e t$ $a l^{25}$ with a final PEG concentration of $2 \%$. The normal range for the $\mathrm{Clq}$ binding assay in serum is $<5.5 \%$ precipitation.

Statistical analysis of data was performed by both the Wilcoxon rank sum test and by ascertaining the $z$ value for 'comparison of proportions'. Significance was assessed at a $p$ value less than $0 \cdot 05$.

\section{Results}

Clinical parameters which were recorded in this study included sex, the presence of characteristic cutaneous lesions (petechial or vesiculopustular), number of joints involved, and the site(s) and frequency of positive cultures for $N$ gonorrhoeae. The clinical findings of 21 patients with DGI are indicated in Table 1 . In the 21 patients with DGI there was a female predominance $(86 \%)$, skin involvement was observed in $43 \%$, and arthritis was present in all patients; single joints were involved in $43 \%$ and multiple joints in $57 \%$. While two thirds of patients had positive urethral or cervical cultures, or both, SF cultures were positive in $39 \%$, blood in $15 \%$, and pharynx in $21 \%$. Rectal culture was positive in one patient. Rectal cultures were not performed routinely where gonococci were identified in other sites.

In eight patients with DGI where simultaneous SF and serum samples were obtained SF complexes were detected by at least one IC assay in five patients $(63 \%)$ and serum IC in four $(50 \%)$ ) (Table 1). Clq binding complexes were present in $\mathrm{SF}$ in three of seven $(43 \%)$, but in none of the sera. With the Raji IFA, complexes containing IgM were detected in three of eight SF and in one of eight sera. Complexes containing IgG were present in one $\mathrm{SF}$ and four sera and complexes containing $\operatorname{IgA}$ in 
818 Shiel Jr, Andrews, Friou, Barada Jr, Scopelitis, Martin

Table 1 Clinical, culture, and immune complex characteristics of patients with disseminated gonococcal infection

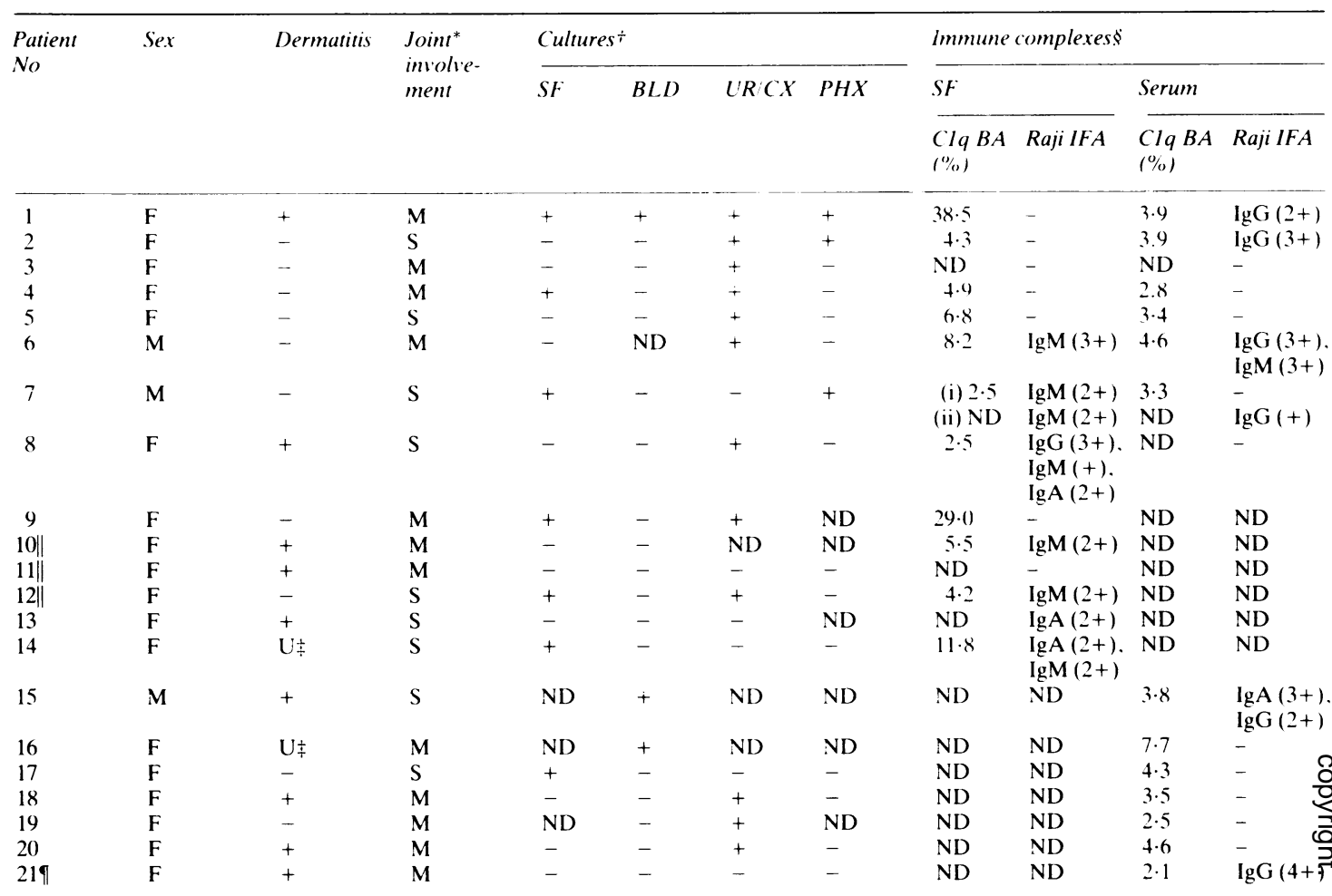

${ }^{*} \mathrm{M}=$ multiple: $\mathrm{S}=$ single.

†SF=synovial fluid; $\mathrm{BLD}=$ blood: $\mathrm{UR} / \mathrm{CX}=$ urethra/cervix; $\mathrm{PHX}=$ pharynx: $\mathrm{ND}=$ not done. $\ddagger \mathrm{U}=$ unknown.

$\S \mathrm{Clq} \mathrm{BA}=\mathrm{Clq}$ binding assay (positive $\geqslant 5 \cdot 5 \%$ ): Raji IFA = Raji immunofluorescent assay.

\|Culture negative.

ๆPositive rectal culture.

one SF. In one patient (No 7), where two SF and serum samples were obtained two days apart, IgM complexes at similar levels were present in both SF samples. In six patients with DGI (Nos 9-14), where SF only was obtained, C1q binding IC were found in three of four samples tested and Raji positive complexes in four of the six. IgM complexes were present in three and $\operatorname{IgA}$ in two, whereas no IgG complexes were detected. Three of these patients were culture negative for gonococci. Serum only was obtained from the remaining seven patients with DGI (Nos 15-21). Only one serum sample had C1q binding complexes and two Raji binding complexes. The Raji bound complexes both contained IgG and one $\operatorname{IgA}$.

When the C1q binding data of the DGI patients were pooled IC were detected in six of $11 \mathrm{SF}(55 \%)$ compared with one of 13 sera $(8 \%)(p<0.05)$ (Table 2). Similar values were obtained in sera from patients with gonococcal urethritis $(17 \%)$. Clq binding IC were detected in five of six SF samples $(83 \%)$ from patients with RA (Table 2 ).

When the immunoglobulin class(es) of IC were

Table 2 Immune complexes in serum and synovial fluid (SF) of patients with disseminated gonococcal infection (DGI), gonococcal urethritis $(G U)$, and rheumatoid arthritis $(R A)$ using the Clq PEG binding assay

\begin{tabular}{|c|c|c|c|}
\hline & & $\begin{array}{l}\text { Number positive* } \\
(\%)\end{array}$ & $\begin{array}{l}\text { Mean }(\%) \text { Clq precipitation } \\
\text { (range, } \%)\end{array}$ \\
\hline DGI & $\begin{array}{l}\text { Serum } \\
\text { SF }\end{array}$ & $\begin{array}{l}1 / 13(8 \%) \\
6 / 11(55 \%) \\
(p<0 \cdot 05) \dagger\end{array}$ & $\begin{aligned} 3.9 & (2 \cdot 1-7 \cdot 7) \\
10 \cdot 7 & (2 \cdot 5-38 \cdot 5)\end{aligned}$ \\
\hline $\begin{array}{l}\text { GU } \\
\text { RA }\end{array}$ & $\begin{array}{l}\text { Serum } \\
\text { SF }\end{array}$ & $\begin{array}{l}1 / 6(17 \%) \\
5 / 6(83 \%)\end{array}$ & $\begin{aligned} 5 \cdot 1 & (3 \cdot 4-6 \cdot 1) \\
17 \cdot 2 & (3 \cdot 5-35 \cdot 8)\end{aligned}$ \\
\hline
\end{tabular}

${ }^{*} \mathrm{Clq}$ binding assay positivity $\geqslant 5.5 \%$ precipitation.

† Determined by the Wilcoxon rank sum test and by the $z$ value for 'comparison of proportions'. 
Table 3 Immunoglobulin class(es) within the Raji cell bound immune complexes in synovial fluid $(S F)$ and serum in patients with disseminated gonococcal infection (DGI)

\begin{tabular}{lllll}
\hline & & $I g M$ & $I g A$ & $I g G$ \\
\hline DGI & SF & $6 / 7$ & $3 / 7$ & $1 / 7$ \\
& Serum & $1 / 6$ & $1 / 6$ & $6 / 6$ \\
\multirow{3}{*}{ Gout/ } & & $(\mathrm{p}<0 \cdot 02)^{*}$ & NS ${ }^{+}$ & $(\mathrm{p}<0 \cdot 003)^{*}$ \\
osteoarthritis & SF & $1 / 5$ & $0 / 5$ & $0 / 5$ \\
& Serum & $1 / 5$ & $0 / 5$ & $0 / 5$ \\
& & NS & NS & NS
\end{tabular}

${ }^{*}$ Determined by the Wilcoxon rank sum test and by the $z$ value for 'comparison of proportions'.

$+N S=$ not significant $(p \geqslant 0 \cdot 05)$.

studied in serum and SF from patients with DGI (Table 3), IgM complexes predominated in SF $(p<0.02)$. Of six patients with positive SF cultures, three had Clq complexes and three IgM Raji binding complexes. It is noteworthy that the highest $\mathrm{Clq}$ binding complexes in the SF of patients with DGI were associated with positive cultures. Of the six positive SF cultures, three patients had single joint involvement and three multiple joints involved. In the controls with gout or degenerative joint disease IC were not significantly increased in serum or SF.

\section{Discussion}

Seeding of synovium and the SF by gonococci may occur in patients with DGI, ${ }^{3-6} 2122$ but in many situations deposition of circulating gonococcal antigen-antibody complexes has been considered largely responsible for the immunopathogenesis of the arthritis. While the presence of circulating IC has been frequently demonstrated in both serum and SF, ${ }^{17-20}$ not all IC assays are able to detect IC in serum and SF of patients with DGI. ${ }^{19}{ }^{20}$ This may relate to the sensitivities and the nature of the IC assays employed as each assay detects complexes based on specific biological and/or physicochemical properties of the complex. The Raji assay detects complexes containing bound $\mathrm{C} 3 \mathrm{~d}$ and to a lesser extent $\mathrm{C} 3 \mathrm{~b},{ }^{23}$ while the $\mathrm{Clq}$ binding assay detects IgM or IgG complexes, or both, which activate the classical complement pathway and fix $\mathrm{Clq}^{25} \mathrm{We}$ have demonstrated the presence of IC in serum and SF of patients with DGI using the Raji IFA and the C1q binding assay. Furthermore, we have also found both a higher incidence and level of IC in SF, as have others. ${ }^{20}$ Using the Raji IFA, we have identified a predominance of IC containing IgM in SF and IC containing IgG in serum. As $39 \%$ of the SF samples from patients with DGI in this study were culture positive for gonococci, as the organism has fastidious growth requirements, ${ }^{7}$ as the organism may be identified in synovium on Gram stain with negative cultures, and as it can also be identified by electron microscopy, ${ }^{21}$ it might be assumed that the incidence of gonococcal synovial seeding is significantly higher than the quoted $30-47 \%$ SF culture positivity. ${ }^{3-6}$

The antigen within the IC in serum and SF of patients with DGI remains undefined. We have attempted to show that the antibody contained within the IC was able to bind to gonococcal antigens: three strains of gonococci were incubated with Raji cells which had DGI IC bound to their surface, but no specific binding of gonococci to Raji cells could be demonstrated.

Our data would support the hypothesis that after the initial mucosal infection with the gonococcus there is a primary $\operatorname{IgA}$ or IgM antibody immune response, or both, to the organism followed by a secondary IgG response. This may then lead to the formation of circulating IC, particularly in those patients where gonococcal antigen(s) or gonococci enter the blood stream. As blood cultures were positive in $15 \%$ of patients in this study it is likely that seeding of synovium with gonococci can readily occur. Whether deposition of circulating IC within synovium results in a synovial inflammatory process which then leads to localisation of circulating gonococci, as proposed by Manicourt and Orloff, ${ }^{20}$ is unclear. For the following reasons, however, we believe that this might not represent the primary mechanism for gonococcal deposition within synovium: $(a)$ the distribution of joint involvement in DGI, which tends to be either monoarticular or asymmetrical oligoarticular, involving both large and small joints. This argues against a primary IC deposition disease, which in humans usually results in a symmetrical polyarthritis as seen in hepatitis B infection, serum sickness, and systemic lupus erythematosus. $^{9-13}$ If primary IC deposition within synovium were responsible for gonococcal deposition, a symmetrical polyarthritis might be expected. (b) The finding of both an increased incidence and level of complexes in SF compared with serum suggests that local antibody production and IC formation may be responsible. This is characteristic of the joint disease of patients with RA. ${ }^{26}(c)$ The higher frequency of IC containing IgM in SF $(p<0.02)$ and of IC containing IgG in serum $(\mathrm{p}<0.003)$ suggests that serum IC are probably not identical with those present in SF. As serum and SF samples were obtained simultaneously, IgM SF complexes occur at a time when IgG complexes are in serum. Local gonococcal antigen-antibody complexes could form within the synovium or SF, or both, after binding of gonococci to locally produced 
antibody. This could then lead to complement activation and initiation of a local inflammatory reaction. It is also possible that the predominant immune response to gonococcal antigen(s) occurs within synovium and that the lower molecular weight IgG complexes pass into serum, with the IgM complexes remaining in the synovium and SF.

Binding of complexes to Raji cells is achieved predominantly via the $\mathrm{C} 3 \mathrm{~d}$ complement receptor ${ }^{23}$ as IgG Fc receptor binding to the Raji cell is of extremely low avidity. Thus if IC are detected in serum or SF these complexes must be able to activate and bind to complement components. Although the Raji cell radioimmunoassay is more sensitive than the Raji IFA, ${ }^{27}$ identification of IgG, IgM, and IgA immunoglobulin classes within the IC by a radioimmunoassay would require ${ }^{125} \mathrm{I}$ labelled heavy chain specific antisera in three separate standardised radioimmunoassays. The presence of $\mathrm{C} 1 \mathrm{q}$ binding complexes in serum or SF indicates that the complexes contain IgM or IgG, or both, and activate the classical complement pathway.

In summary, our data support the hypothesis that gonococci localise in the joints of patients with DGI and lead to local antibody production and hence local IC formation within synovium and SF. The IC detected in SF do not appear to originate from serum since a difference between Ig classes within the complexes is found.

We wish to thank Nell Greco, Susan Burns, and Linda Walter for their word processing expertise and Heidi Dick and Gary Mirick for their valuable technical assistance. This work was supported by grant AM-11766 from the National Institutes of Health and grants from the Arthritis Foundation.

\section{References}

1 Keiser H L, Ruben F L, Wolinsky E, Kushner I. Clinical forms of gonococcal arthritis. N Engl J Med 1968; 279: 234-40.

2 Brandt K D, Cathcart E S, Cohen A S. Gonococcal arthritis. Arthritis Rheum 1974; 17: 503-10.

3 Seifert M H, Warin A P, Miller A. Articular and cutaneous manifestations of gonorrhoea. Ann Rheum Dis 1974; 33: 140-6.

4 Cooke C L, Owen D S, Irby R, Toone E. Gonococcal arthritis. JAMA 1971; 217: 204-5.

5 Brogadir S P, Schimmer B M, Myers A R. Spectrum of the gonococcal arthritis-dermatitis syndrome. Semin Arthritis Rheum 1979; 8: 177-83.

6 O'Brien J P, Goldenberg D L, Rice P A. Disseminated gonococcal infection: a prospective analysis of 49 patients and a review of pathophysiology and immune mechanisms. Medicine (Baltimore) 1983; 62: 395-406.

7 Knapp J S, Holmes K K. Disseminated gonococcal infections caused by Neisseria gonorrhoeae with unique nutritional requirements. J Infect Dis 1975; 132: 204-8.

8 Andrews B S, Eisenberg R A, Theofilopoulos A N, et al. Spontaneous murine lupus-like syndromes. Clinical and im- munopathological manifestations in several strains. $J$ Exp Med 1978: 148: 1198-215.

9 Duffy J, Lidsky M D. Sharp J T, et al. Polyarthritis, polyarteritis, and hepatitis B. Medicine (Baltimore) 1976: 55: $19-37$.

10 Sergent J S. Extrahepatic manifestations of hepatitis B infection. Bull Rheum Dis 1983; 33: 1-3.

11 Dixon F J. Vasquez J J, Weigle W O. Cochrane C G Pathogenesis of serum sickness. Arch Pathol 1958; 65: 18-27.

12 Theofilopoulos A N. Andrews B S. Urist M M. Morton D L. Dixon $F \mathbf{J}$. The nature of immune complexes in human cancer sera. J Immunol 1977; 119: 657-63.

13 Cochrane C G, Koffler D. Immune complex disease in experimental animals and man. Adv Immunol 1973; 16: 185-253.

14 Carvalho E M. Andrews B S, Martinelli R, Dutra M, Rocha H. Circulating immune complexes and rheumatoid factor in schistosomiasis and visceral leishmaniasis. Am J Trop Med Hyg 1983; 32: 61-8.

15 Andrews B S. Penny R. Immune complexes in human disease. IMJ 1978; 154: 146-53.

16 Izui S, Lambert $\mathrm{P} \mathrm{H}$, Miescher P A. In vitro demonstration of a particular affinity of glomerular basement membrane and collagen for DNA. A possible basis for local formation of DNA anti-DNA complexes in systemic lupus erythematosus. $J$ Exp Med 1976; 144: 428-43.

17 Goldman J A. Thompson S E III, Jacobs N. Casey H L. Daugharty $\mathrm{H}$, Wilson $\mathrm{C} \mathrm{H}$. Detection of circulating immune complexes using platelet aggregation in patients with disseminated gonococcal infection (DGI). Arthritis Rheum 1975; 18: 402.

18 Walker L C. Ahlin T D. Tung KSK, Williams R C J Circulating immune complexes in disseminated gonorrhe ? infection. Ann Intern Med 1978; 89: 28-33.

19 Ludivico C L, Myers A R. Survey for immune complexes it disseminated gonococcal arthritis-dermatitis syndrome. Arthritis Rheum 1979; 22: 19-24.

20 Manicourt D H, Orloff S. Gonococcal arthritis-dermatitis syndrome: study of serum and synovial fluid immune complex levels. Arthritis Rheum 1982; 25: 574-8.

21 Garcia-Kutzbach A. Beachey E H. Chandler R W. Townes A $S$, Masi A T. Identification of Neisseria gonorrhoeae in synovial membrane by electron microscopy. J Infect Dis 1974; 130: 183-6.

22 Layfer L F, Parciancy R K. Trenholme G M. Diagnosis of gonococcal arthritis by counterimmunoelectrophoresis: detection of antigen and antibody in serum and synovial fluid. Arthritis Rheum 1978; 21: 572-3.

23 Theofilopoulos A N, Wilson C B, Bokisch V A, Dixon F J. Binding of soluble immune complexes to human lymphoblastoid cells. II. Use of Raji cells to detect circulating immune complexes in animal and human sera. $J$ Exp Med 1974; 140: $1230-44$.

24 Cunningham P H, Andrews B S, Davis J S IV. Immune complexes in progressive systemic sclerosis and mixed connective tissue disease. J Rheumatol 1980; 7: 301-8.

25 Zubler R H, Lange G, Lambert P H, Miescher P A. Detection of immune complexes in unheated sera by a modified ${ }^{125} \mathrm{I}-\mathrm{Clq}$ binding test. Effect of heating on the binding of $\mathrm{Clq}$ by immune complexes and application of the test to systemic lupus erythematosus. $J$ Immunol 1976; 116: 232-5.

26 Jones V, Taylor P C R, Jacoby R K, Wallington T B. Synovial synthesis of rheumatoid factors and immune complex constituents in early arthritis. Ann Rheum Dis 1984; 43: 235-9.

27 Theofilopoulos A N, Wilson C B, Dixon F J. The Raji cell radioimmune assay for detecting immune complexes in human sera. J Clin Invest 1976; 57: 169-82. 